\title{
Cross-Regional Connectedness in the United States' Housing Market
}

\author{
Wen Yin $^{1}$ \\ ${ }^{1}$ Statistics Department, Graduate School of Arts and Sciences, Columbia University, New York, USA
}

\begin{abstract}
The interconnectedness of markets is a useful measure of risk and therefore an indicator of economic stability. In this paper, the interconnectedness among housing markets in different metropolitan areas was analyzed. Interconnectedness between the housing market and other markets were also calculated. In regional studies, West Coast housing markets were found to be the most influential on housing markets elsewhere. Interestingly, overall connectedness across regions steadily increased prior to the subprime mortgage crisis, representing a systematic risk increase. When analyzing diverse markets in relation to the housing market, the stock market was found to have the highest interconnectedness, suggesting that financial health of stock market depend on financial health of housing market. The increased systematic risk due to high housing market interconnectedness coupled with the interdependence between the stock market and the housing market were key indicators of the subprime mortgage crisis. Such measures should be monitored in the future to avoid a similar economic disaster.
\end{abstract}

\section{Introduction}

It is true to state that the United States has recovered from the subprime mortgage crisis that occurred ten years ago. Diverse indexes (such as S\&P 500 and Nasdaq) witnessed all-time highs in the initial half of 2018. Nevertheless, investors and policy makers should not overlook the potential crises, which arise from risks in the housing market. For purposes of preventing mortgage crises of that nature, this research comprehensively analyzes the effect of the housing market in 20 cities in the United States. Besides, changes before, in the course of and upon the end of the subprime mortgage crisis are a reflection of the impact of connectedness among the said housing markets. Briefly, the objective of undertaking this study is to examine changes in the housing markets connectedness among major cities across the U. S., together with the impacts of the said changes. The outcomes of the study will enlighten on the nature of the housing markets risks, any other risks that are likely linked to the financial markets, and the uncertainty of the risks that face the economy as a whole.

\section{Literature Review}

Diebold and Yilmaz suggested the use of another approach to the measure the quantification of the connectedness and the overall market size effect[4]. Besides, the method allows the illustration of the changes in dynamic connectedness. This paper will adopt the method that was proposed by Diebold and Yilmaz by making use of house price indices data on twenty metropolitan areas around U.
S. from January, 1991 to April, 2018 in order to analyze the reviewed cities' connectedness[4].

Most studies investigate the correlation of housing markets around the United States. Some of the studies verify that real estate markets in various states are considerably correlated[2,7,8]. Other studies object the concept of long-term convergence and spillover impacts in U. S. state housing prices[6]. Nonetheless, the correlation among various cities' housing markets around the U. S. is essentially supported by empirical evidence.

The advent of the subprime mortgage crisis indicates the importance of some issues such as pointing out systematic risks found in the housing market. On the point of premier research topic, risks of systematic nature are identified through the establishment of the correlation that exists among various housing markets. The general association among the various regional housing markets is explainable theoretically through the pertinent literature. It is also substantiated empirically to be contained by markets of housing nature in cities found in the United States[5]. Nonetheless, there is scant research concerning the dynamic and real-time measurements of the housing markets connectedness in the cities.

Majority of the studies focus on offering explanations about the average correlation between the markets for every data period or reviewing if such a correlation illustrates structural breaks to define changes in connectedness in the course of a time period[5,8]. Crises in the housing market cannot possibly be identified simply by approximating systematic risks during general circumstances, because the U. S. has undergone a financial crisis which was caused by real estate risks(the so-called subprime mortgage crisis). In that regard, it is necessary to 
obtain dynamic connectedness that can be utilized to thoroughly review changes in housing market connectedness in cities across the United States. Other relevant issues, like the dynamic impacts of systematic risks during the mortgage crisis and increased housing markets connectedness among the major cities should also be analyzed.

In regards to the next research topic concerning the effects that the housing market has on other markets and on the general economy, it is worth noting that housing market connectedness affects the information distribution in the overall economy. From this crisis (the subprime mortgage crisis), it is clear that the risks found in the housing markets can easily get to other markets. However, this has been ignored for a long time and the main reason for this is because research has been directed towards assessing the effects on wealth between the stock and housing markets, or in the conclusion that the two markets could be segmented. Just a little number of studies ascertain that funds flow to housing markets from stock markets is possibly attributable to the investment safety requirements. Concerning issues on risks in housing markets, establishing that the housing market's high systematic risk spreads over to other markets, would imply increased connectedness between housing markets and other markets.

A great percentage of the past studies have drawn the conclusion that central banks have the potential of responding to asset price fluctuations[7,8]. The greater the linkage among the housing markets means increasing the regional housing markets risk. Monetary policies can also respond to the increases in systematic risks[8]. However, it has to be noted that the data used in this study was obtained from a period during which there was a housing bubble. Additionally, the subprime mortgage crisis could have made the Federal Reserve to opt for the substantial modification of its monetary. In that respect, it is possible to reach the conclusion that total connectedness is likely to have impact on the growth rate of money and findings that are actually consistent with those obtained in other past studies.

\section{Empirical Method}

In order to establish the correlation in the different housing markets, the research utilized the structure described in Diebold's paper on the connectedness measurement[4]. The connectedness methodology is actually based on forecasting error variance decomposition that has been generalized. Like orthogonalized variance decomposition, the said generalized variance decomposition mainly relies on a data-based identification system. Nevertheless, it happens to be insensitive to the variable ordering, as it permits correlated shocks and utilizes the historically observed error distribution.

Utilizing the 20 cities' house price indices for the period between January 1991 and April 2018, the thesis offered an analysis of the changes and impact of housing markets connectedness in major cities in the United States[7]. The spatial changes of housing markets in the major U. S. cities indicate that from all the samples, West Coast cities had the most influential housing markets. Spatial distribution of the aforementioned influence was impacted by subprime mortgage crisis as few cities have optimistic net impacts in the course of the crisis period.

Afterwards, the VAR mode together with impulse response function was used to carry out an analysis and demonstration of the linkage between the prevailing money supply and the housing market systematic risk. What is more, in the study, subprime mortgage market index was utilized as a default risk measure, given that the most recent housing crisis in the U. S. was brought about by subprime mortgages. The findings were set to offer insight into if the housing markets have effects on the economy in general and other markets come about from the increase in monetary control, in addition to the default risk brought about by systematic risks.

\section{Empirical Results and Discussion}

The housing data that was used in this research was gathered from Case-Shiller/ S\&P Home Price Indices. Monthly house price indices that have been seasonally adjusted for the cities as established by the Case-Shiller/ S\&P Composite 20 were adopted[5]. Graphs were used to exhibit the fluctuations in house price indices.

Prior to approximating the dynamic connectedness, an indicator was used which has been conventionally utilized in approximating correlations between markets. The correlation coefficients between the twenty major cities' housing returns were gathered and listed in table 1 . The interactions among the housing market returns (connectedness of the said markets) were tabulated in table 2. In respect to the available data, the regional housing connectedness increased continuously prior to October, 2007. This indicates that the housing market systematic risk in the United States was increasing during that period. Systematic risk peaked during the 2007 subprime mortgage crisis prior to declining substantially. There was deterioration up to October, 2008, after which there was a rise up to the year 2010 in the month of August. In this period, there can be said to have been two financial crises labeled as the infamous European sovereign debt crisis and the Lehman Brothers bankruptcy. In 2007, the housing market was the one that led to the financial crisis.

This systematic risk was helpful in the assessment of the general market risk in that period. This can be explained by the weakened economic performance at this time which led to the decision by the United States Federal Reserve to employ quantitative easing with the aim of stimulating the market. The aforementioned monetary policy should have made available sufficient amount of capital in the market, thereby resulting in an increase in the systematic risk.

Table1. Correlation Coefficients

\begin{tabular}{|c|cccccccccccccccccccc|}
\hline City & R1 & R2 & R3 & R4 & R5 & R6 & R7 & R8 & R9 & R10 & R11 & R12 & R13 & R14 & R15 & R16 & R17 & R18 & R19 & R20 \\
\hline AZ-Phoenix & 1.00 & 0.81 & 0.69 & 0.76 & 0.52 & 0.77 & 0.89 & 0.85 & 0.54 & 0.65 & 0.47 & 0.65 & 0.70 & 0.51 & 0.73 & 0.64 & 0.41 & 0.78 & 0.45 & 0.78 \\
CA-Los Angeles & 0.81 & 1.00 & 0.91 & 0.80 & 0.49 & 0.85 & 0.88 & 0.82 & 0.60 & 0.69 & 0.59 & 0.63 & 0.69 & 0.45 & 0.88 & 0.75 & 0.41 & 0.66 & 0.37 & 0.68 \\
CA-San Diego & 0.69 & 0.91 & 1.00 & 0.83 & 0.54 & 0.81 & 0.80 & 0.72 & 0.52 & 0.64 & 0.67 & 0.60 & 0.70 & 0.38 & 0.81 & 0.71 & 0.41 & 0.54 & 0.38 & 0.56 \\
CA-San Francisco & 0.76 & 0.80 & 0.83 & 1.00 & 0.67 & 0.74 & 0.76 & 0.72 & 0.59 & 0.65 & 0.64 & 0.63 & 0.71 & 0.45 & 0.68 & 0.62 & 0.44 & 0.62 & 0.49 & 0.64
\end{tabular}




\begin{tabular}{|c|c|c|c|c|c|c|c|c|c|c|c|c|c|c|c|c|c|c|c|c|}
\hline CO-Denver & 0.52 & 0.49 & 0.54 & 0.67 & 1.00 & 0.44 & 0.50 & 0.55 & 0.53 & 0.53 & 0.58 & 0.58 & 0.60 & 0.41 & 0.47 & 0.41 & 0.47 & 0.47 & 0.65 & 0.56 \\
\hline DC-Washington & 0.77 & 0.85 & 0.81 & 0.74 & 0.44 & 1.00 & 0.84 & 0.78 & 0.47 & 0.70 & 0.66 & 0.58 & 0.68 & 0.34 & 0.73 & 0.80 & 0.44 & 0.58 & 0.36 & 0.56 \\
\hline FL-Miami & 0.89 & 0.88 & 0.80 & 0.76 & 0.50 & 0.84 & 1.00 & 0.89 & 0.54 & 0.72 & 0.58 & 0.64 & 0.72 & 0.48 & 0.80 & 0.77 & 0.40 & 0.72 & 0.40 & 0.75 \\
\hline FL-Tampa & 0.85 & 0.82 & 0.72 & 0.72 & 0.55 & 0.78 & 0.89 & 1.00 & 0.57 & 0.73 & 0.57 & 0.61 & 0.66 & 0.49 & 0.77 & 0.74 & 0.41 & 0.77 & 0.46 & 0.76 \\
\hline GA-Atlanta & 0.54 & 0.60 & 0.52 & 0.59 & 0.53 & 0.47 & 0.54 & 0.57 & 1.00 & 0.68 & 0.47 & 0.59 & 0.58 & 0.50 & 0.57 & 0.50 & 0.37 & 0.59 & 0.50 & 0.62 \\
\hline IL-Chicago & 0.65 & 0.69 & 0.64 & 0.65 & 0.53 & 0.70 & 0.72 & 0.73 & 0.68 & 1.00 & 0.66 & 0.72 & 0.71 & 0.49 & 0.65 & 0.74 & 0.46 & 0.69 & 0.48 & 0.69 \\
\hline MA-Boston & 0.47 & 0.59 & 0.67 & 0.64 & 0.58 & 0.66 & 0.58 & 0.57 & 0.47 & 0.66 & 1.00 & 0.58 & 0.67 & 0.30 & 0.52 & 0.66 & 0.45 & 0.41 & 0.43 & 0.42 \\
\hline MI-Detroit & 0.65 & 0.63 & 0.60 & 0.63 & 0.58 & 0.58 & 0.64 & 0.61 & 0.59 & 0.72 & 0.58 & 1.00 & 0.72 & 0.47 & 0.64 & 0.52 & 0.40 & 0.57 & 0.49 & 0.60 \\
\hline MN-Minneapolis & 0.70 & 0.69 & 0.70 & 0.71 & 0.60 & 0.68 & 0.72 & 0.66 & 0.58 & 0.71 & 0.67 & 0.72 & 1.00 & 0.50 & 0.61 & 0.65 & 0.43 & 0.60 & 0.52 & 0.61 \\
\hline NC-Charlotte & 0.51 & 0.45 & 0.38 & 0.45 & 0.41 & 0.34 & 0.48 & 0.49 & 0.50 & 0.49 & 0.30 & 0.47 & 0.50 & 1.00 & 0.48 & 0.39 & 0.27 & 0.62 & 0.45 & 0.65 \\
\hline NV-Las Vegas & 0.73 & 0.88 & 0.81 & 0.68 & 0.47 & 0.73 & 0.80 & 0.77 & 0.57 & 0.65 & 0.52 & 0.64 & 0.61 & 0.48 & 1.00 & 0.67 & 0.38 & 0.66 & 0.36 & 0.72 \\
\hline NY-New York & 0.64 & 0.75 & 0.71 & 0.62 & 0.41 & 0.80 & 0.77 & 0.74 & 0.50 & 0.74 & 0.66 & 0.52 & 0.65 & 0.39 & 0.67 & 1.00 & 0.40 & 0.58 & 0.28 & 0.60 \\
\hline OH-Cleveland & 0.41 & 0.41 & 0.41 & 0.44 & 0.47 & 0.44 & 0.40 & 0.41 & 0.37 & 0.46 & 0.45 & 0.40 & 0.43 & 0.27 & 0.38 & 0.40 & 1.00 & 0.40 & 0.47 & 0.35 \\
\hline OR-Portland & 0.78 & 0.66 & 0.54 & 0.62 & 0.47 & 0.58 & 0.72 & 0.77 & 0.59 & 0.69 & 0.41 & 0.57 & 0.60 & 0.62 & 0.66 & 0.58 & 0.40 & 1.00 & 0.53 & 0.84 \\
\hline TX-Dallas & 0.45 & 0.37 & 0.38 & 0.49 & 0.65 & 0.36 & 0.40 & 0.46 & 0.50 & 0.48 & 0.43 & 0.49 & 0.52 & 0.45 & 0.36 & 0.28 & 0.47 & 0.53 & 1.00 & 0.51 \\
\hline WA-Seattle & 0.78 & 0.68 & 0.56 & 0.64 & 0.56 & 0.56 & 0.75 & 0.76 & 0.62 & 0.69 & 0.42 & 0.60 & 0.61 & 0.65 & 0.72 & 0.60 & 0.35 & 0.84 & 0.51 & 1.00 \\
\hline
\end{tabular}

Table2. Full-Sample Connectedness Table

\begin{tabular}{|c|c|c|c|c|c|c|c|c|c|c|c|c|c|c|c|c|c|c|c|c|c|}
\hline City & R1 & R2 & R3 & R4 & R5 & R6 & R7 & R8 & R9 & R10 & R11 & R12 & R13 & R14 & R15 & R16 & R17 & R18 & R19 & R20 & From \\
\hline AZ-Phoenix & 31.7 & 4 & 8 & 9.3 & 9 & 3.8 & 14.9 & 3 & 2.8 & 0.1 & 0.4 & 0.5 & 0.4 & 0.5 & 1 & 2.3 & 0.8 & 1 & 2.9 & 3.8 & 68 \\
\hline CA-Los Angeles & 11.3 & 27.2 & 14.8 & 8.4 & 5.7 & 1.8 & 8.1 & 4.8 & 0.5 & 0.2 & 3.8 & 0.1 & 0.2 & 1.5 & 5.3 & 0.6 & 2.3 & 0.7 & 1.5 & 1.5 & 73 \\
\hline CA-San Diego & 5.9 & 22.2 & 25.6 & 10.8 & 7.6 & 0.9 & 5.5 & 3.2 & 0.1 & 0.2 & 5.5 & 0.1 & 0.7 & 2.4 & 3.7 & 0.3 & 2.5 & 0.4 & 0.8 & 1.6 & 74 \\
\hline CA-San Francisco & 9.1 & 10.5 & 14 & 26.8 & 9.2 & 1.8 & 6.7 & 2.5 & 0.4 & 0.6 & 1.4 & 0.2 & 0.3 & 2.6 & 1.9 & 2.9 & 2.7 & 1.1 & 2.3 & 2.9 & 73 \\
\hline CO-Denver & 4.5 & 1 & 9.8 & 15.7 & 35.8 & 2.2 & 4.2 & 4.1 & 0.2 & 0.5 & 3.7 & 0.6 & 0.6 & 4.1 & 0.5 & 0.5 & 1 & 0.5 & 6.2 & 4.5 & 64 \\
\hline DC-Washington & 8.3 & 16.5 & 11.2 & 9.4 & 5 & 17.2 & 8.6 & 4.6 & 1 & 0.7 & 4.1 & 0.6 & 0.7 & 0.8 & 1.5 & 2.1 & 2.6 & 2.3 & 1.1 & 1.8 & 83 \\
\hline FL-Miami & 16.4 & 12.2 & 8.5 & 7.8 & 7.6 & 2.9 & 21.3 & 7.7 & 1.2 & 0.3 & 2.8 & 0.4 & 1.8 & 0.1 & 2.5 & 0.5 & 0.8 & 0.9 & 2.1 & 2.1 & 79 \\
\hline FL-Tampa & 13.5 & 7.4 & 5.8 & 7.2 & 9.1 & 2.4 & 11.6 & 23 & 1.7 & 1 & 3.1 & 0.3 & 0.3 & 0.5 & 2.3 & 0.9 & 1.8 & 2.1 & 3.3 & 2.7 & 77 \\
\hline GA-Atlanta & 5 & 4.4 & 6.1 & 7.7 & 6.7 & 0.2 & 2.6 & 3.8 & 29.2 & 1.7 & 2.3 & 2.6 & 0.4 & 5.4 & 3.4 & 1.3 & 2.5 & 1.8 & 7.5 & 5.2 & 71 \\
\hline IL-Chicago & 5.2 & 6.2 & 5.7 & 7.8 & 5.5 & 5.2 & 5.7 & 7.8 & 4.2 & 13.6 & 2.7 & 4.2 & 3 & 5.7 & 1.4 & 2.3 & 1.9 & 2.8 & 4 & 5.1 & 86 \\
\hline MA-Boston & 1.7 & 6.5 & 11 & 11.4 & 12.1 & 2.4 & 3.1 & 3.7 & 0.4 & 2 & 23.1 & 0.9 & 2.3 & 4.5 & 0.7 & 4.8 & 4.4 & 1.2 & 1.2 & 2.8 & 77 \\
\hline MI-Detroit & 7.4 & 3.2 & 9 & 8.4 & 11.2 & 1.1 & 4.3 & 1.4 & 1.9 & 7 & 2.2 & 23.3 & 5.8 & 5 & 2.2 & 1.2 & 0.1 & 0.6 & 2.3 & 2.3 & 77 \\
\hline MN-Minneapolis & 8.1 & 4.1 & 9 & 9.9 & 11.9 & 2.6 & 7.4 & 4.8 & 0.8 & 1.9 & 2.5 & 2.1 & 16.3 & 3.3 & 0.9 & 1.7 & 2.4 & 1.9 & 3.8 & 4.7 & 84 \\
\hline NC-Charlotte & 7.5 & 2.4 & 3.3 & 5.5 & 2.7 & 0.8 & 4.6 & 3.1 & 2.6 & 0.9 & 4.3 & 0.1 & 3.3 & 29.7 & 2.9 & 2.4 & 1.1 & 7.3 & 3.8 & 11.6 & 70 \\
\hline NV-Las Vegas & 8.3 & 22.3 & 17.2 & 3.6 & 5 & 0.2 & 4.8 & 1.8 & 0.2 & 0.1 & 2.3 & 0.7 & 0.9 & 4.4 & 22 & 0.3 & 0.3 & 0.3 & 0.6 & 4.4 & 78 \\
\hline NY-New York & 3.9 & 11.3 & 6.6 & 6.5 & 4.1 & 6.3 & 6 & 10.2 & 1 & 1.3 & 6.8 & 0.6 & 1.2 & 2.6 & 0.7 & 22.5 & 5.2 & 0.5 & 0.8 & 1.8 & 77 \\
\hline OH-Cleveland & 4.4 & 3.3 & 5.3 & 4.1 & 8 & 3.9 & 4 & 4.5 & 1.3 & 1 & 3.6 & 0.5 & 2 & 3.3 & 1.1 & 1.3 & 38 & 1.2 & 5.4 & 3.6 & 62 \\
\hline OR-Portland & 13.8 & 2.1 & 1.7 & 5.9 & 5.5 & 3.1 & 8.7 & 7.3 & 1.2 & 0.5 & 0.6 & 0.6 & 0.3 & 1.8 & 3 & 0.9 & 2.5 & 23.9 & 8.3 & 8.2 & 76 \\
\hline TX-Dallas & 5.8 & 0.4 & 4.5 & 7.6 & 11.4 & 3.2 & 5.1 & 3.6 & 1.5 & 0.7 & 2.9 & 0.2 & 1.7 & 3.4 & 0.9 & 1 & 3.4 & 6.4 & 29.8 & 6.4 & 70 \\
\hline WA-Seattle & 15 & 2.9 & 4.2 & 7.4 & 6.1 & 1.2 & 8.3 & 5.7 & 1.2 & 0.2 & 0.3 & 0.2 & 0.8 & 3 & 4.4 & 0.9 & 0.2 & 5.5 & 5.3 & 27.2 & 73 \\
\hline To & 155 & 143 & 156 & 154 & 144 & 46 & 124 & 88 & 24 & 21 & 55 & 15 & 27 & 55 & 40 & 28 & 39 & 39 & 63 & 77 & $74.60 \%$ \\
\hline
\end{tabular}

Note Italicized numbers represent the directional contribution to or from other markets. The \% (in bold)in the lower right bottom corner represents the total connectedness

Afterwards, a connectedness analysis as described in Diebold's paper was undertaken to establish if the connectedness dynamics inside housing markets was linked to the housing markets connectedness and other markets. These analyses were used to determine if the regional housing markets' systematic risks are attributable to the housing market's ability to disseminate information. In that regard, pairwise estimations of the connectedness among housing, bond, stock, foreign markets and currency markets in the United States were calculated. The relevant data was obtained from S\&P 500 Index, USD index, CaseShiller HPI Composite and U. S. 10-year bond yield. The simple statistics of the aforementioned market datasets were presented in table 3 , illustrating that the highest fluctuation was witnessed in the stock markets. Utilizing index return data of the aforementioned markets, an estimation of the full-sample connectedness was done, as it is illustrated in table 4. Subsequently, a 24-month rolling-sample windows was used to obtain the changes in dynamic connectedness, as demonstrated in figure 1 .

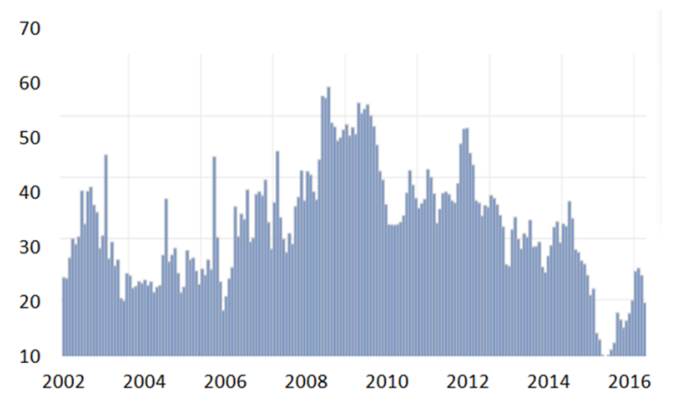

Fig1. Connectedness among Four Diverse Markets

Housing market connectedness with other markets is markedly higher than interconnectedness among other markets, with the exception of the interconnectedness of foreign exchange markets and the stock market. The strong link between the two markets is likely driven by the strong correlation between U. S. stock market trends and trends in exchange rates since the two are directly linked. Interestingly, the connectedness between the housing and 
stock markets and the housing and foreign exchange markets are the lowest values observed. Such a finding may at first seem paradoxical since the subprime mortgage crisis drove an international recession that included the stock market. However, the strong link between the stock and foreign exchange markets and other markets coupled with the strong link between the housing market and other markets explains the connection via those intermediaries. Overall, strong market interconnectedness clearly indicates a risk when one particular market fails as was observed during the 2008 U. S. financial crisis.

Table3. Descriptive Statistics for Four Markets Data

\begin{tabular}{|c|c|c|c|c|}
\hline Market & $\begin{array}{c}\text { Housing } \\
\text { Market } \\
\text { (Index) }\end{array}$ & $\begin{array}{c}\text { Stock } \\
\text { market } \\
\text { (Index) }\end{array}$ & $\begin{array}{c}\text { Bond } \\
\text { market } \\
(\%)\end{array}$ & $\begin{array}{c}\text { Foreign } \\
\text { exchange } \\
\text { market } \\
\text { (Index) }\end{array}$ \\
\hline Mean & 161.14 & 1460.92 & 3.52 & 90.08 \\
\hline Median & 159.48 & 1321.67 & 3.59 & 87.06 \\
\hline Maximum & 210.77 & 2823.81 & 6.66 & 120.28 \\
\hline Minimum & 100.59 & 735.09 & 1.46 & 71.80 \\
\hline Std. Dev. & 29.31 & 462.42 & 1.25 & 12.14 \\
\hline Skewness & -0.07 & 0.97 & 0.23 & 0.79 \\
\hline Kurtosis & 1.98 & 3.13 & 2.11 & 2.74 \\
\hline
\end{tabular}

Table4. Connectedness between Markets

\begin{tabular}{|c|c|c|c|c|c|}
\hline Connectedness & $\begin{array}{c}\text { Housing } \\
\text { Market }\end{array}$ & $\begin{array}{c}\text { Stock } \\
\text { market }\end{array}$ & $\begin{array}{c}\text { Bond } \\
\text { market }\end{array}$ & $\begin{array}{c}\text { Foreign } \\
\text { exchange } \\
\text { market }\end{array}$ & Other \\
\hline Housing market & 84.5 & 9.1 & 5.1 & 1.3 & 16 \\
\hline Stock market & 0.9 & 84.3 & 4.2 & 10.7 & 16 \\
\hline Bond market & 2.3 & 10.8 & 84.9 & 2.0 & 15 \\
\hline $\begin{array}{c}\text { Foreign exchange } \\
\text { market }\end{array}$ & 0.3 & 11.5 & 1.8 & 86.4 & 14 \\
\hline $\begin{array}{c}\text { Contribution to } \\
\text { others }\end{array}$ & 3 & 31 & 11 & 14 & 60 \\
\hline $\begin{array}{c}\text { Contribution } \\
\text { including own }\end{array}$ & 88 & 116 & 96 & 100 & $15.0 \%$ \\
\hline
\end{tabular}

\section{Conclusion}

By using 20 cities' overall house price indices in the United States between the period of January 1991 and April 2018, an analysis was conducted on the various amendments and effects of the housing markets' connectedness in the U. S., specifically in the country's major cities. The spatial changes in the impacts of housing markets in major American cities indicate that from the obtained samples, the West Coast cities' housing markets turn out to be highly influential. The West Coast cities' influence tends to increase upon the end of subprime crisis when a comparison is made to the period before the crisis, perhaps due to the fact that the houses in West Coast cities realize recovery more quickly as compared to the others. Most importantly, from the study, it is established that the housing market systematic risks linkage among the United States' cities are connected to subprime mortgage crisis, in addition to the Lehman Brothers financial crisis, which implies that the linkage between the cities' housing markets most likely has a warning pointer for market risks. Further studies could analyze housing data from non-U. S. countries to determine if similar trends apply globally. Such trend could also be used to consider if U. S. subprime mortgages prior to the 2008 economic crisis contributed to housing market connectedness through comparisons to interconnectedness trends in non-U. S. countries.
Analyses that considered pairwise connectedness among the housing market and other markets found high connectedness with non-stock markets and the housing market, but relatively low connectedness between the stock markets and the housing market. However, evidence from past recessions indicates a strong connection between the stock market and the housing market, implying a more complex relationship than captured in this study. Future work should include analyses to account for such relationships, such as considering connections between markets that occur through an intermediary market as appears to be happening with the stock and housing markets.

Overall, this paper highlights key insights into housing market trends and presents market interconnectedness as one potential indicator of recession risk. Strong interconnectedness among various markets further indicates that health of any one market could affect the whole market. Therefore, ensuring overall economic health requires protecting the health of all subeconomies.

\section{Acknowledgment}

The support and motivation to complete this research was through Professor Pierre Clare, and his insights were deeply appreciated. Teacher Jingjing Zhang provided critical review of the manuscript in progress and provided invaluable feedback. Sincerest thanks to both, without whom completing this project would not have been possible.

\section{References}

1. Ashley, Richard, and Guo Li. "Re-examining the impact of housing wealth and stock wealth on retail sales: Does persistence in wealth changes matter?" Journal of Housing Economics 26 (2014): 109-118.

2. Bahmani-Oskooee, Mohsen, and Seyed Hesam Ghodsi. "Asymmetric causality between the US housing market and its stock market: Evidence from state level data." The Journal of Economic Asymmetries 18 (2018): e00095.

3. Calomiris, C. W., Longhofer, S. D. and Miles, W. (2013). The Housing Wealth Effect: The Crucial Roles of Demographics, Wealth Distribution and Wealth Shares. Critical Finance Review, 2(1), 49-99.

4. Diebold, Francis X., and Kamil Yilmaz. "On the network topology of variance decompositions: Measuring the connectedness of financial firms." Journal of Econometrics 182.1 (2014): 119134.

5. Kallberg, Jarl G., Crocker H. Liu, and Paolo Pasquariello. "On the price comovement of US residential real estate markets." Real Estate Economics 42.1 (2014): 71-108.

6. Nyakabawo, Wendy, et al. "Temporal causality between house prices and output in the US: A bootstrap rolling-window approach." The North 
American Journal of Economics and Finance 33 (2015): 55-73.

7. Pijnenburg, Katharina. "The spatial dimension of US house prices." Urban Studies 54.2 (2017): 466-481.

8. Simo-Kengne, Beatrice D., et al. "Evolution of the monetary transmission mechanism in the US: The role of asset returns." The Journal of Real Estate Finance and Economics 52.3 (2016): 226-243. 